\title{
Division of Basic Sciences
}

National Cancer Institute

\section{Source}

National Cancer Institute. Division of Basic Sciences. NCI Thesaurus. Code C19215.

This division (1) plans, directs, coordinates and evaluates the Institute's intramural programs in basic science relating to cellular, molecular, genetic, biochemical and immunological mechanisms relevant to the understanding, diagnosis and treatment of cancer; (2) establishes program priorities, allocates resources, integrates the projects of the various laboratories, evaluates program effectiveness and represents the division in management and scientific decision-making meetings within the Institute; (3) identifies the need for and establishes new intramural research activities; (4) supports training and research opportunities in the basic sciences for young investigators; (5) supports the translational research by integ rating and coordinating divisional research activities with other $\mathrm{NCl}$ divisions, with the institutes, centers and divisions within the $\mathrm{NIH}$ as well as with the private sector and the academic research community. ( $\mathrm{NCl})$ 